\title{
粉体圧縮に関する基礎的研究*
}

川北公 夫**

\section{Fundamental Research on Powder Compression}

by

\section{Kimio KaWAKITA}

(Faculty of Engineering, Hosei University, Koganei)

\section{1 ま えがき}

粉体の充てんおよび圧縮の現象を基本的に考察する と, 粉体粒子の基礎物性との関連性は重要な問題であ るが，一応これを別問題として考学ると，計測上大別 して次の二つの方向がある。

(a) 圧力とそれに伴う容積変化との関係を表わす理 論式を導く。

(b) 圧粉体内部の応力分布, 密度分布を表わす理論 式を導く.

それぞれにいくつかの理論が発表されているが, 前 者の(a)の方向として著者はすでに次に示す圧縮式を発 表した。

$$
C=\left(V_{0}-V\right) / V_{0}=a b P /(1+b P)
$$

ここにCは粉体の見掛村容積減少度, $V_{0}$ は初期容 積, $V$ は加圧下に护ける容積, $P$ は圧力, $a$ および $b$ は使用した粉体の特性定数である。(1)式を変形すると，

$$
P / C=1 /(a \cdot b)+P / a
$$

となり, $P / C$ と $P$ とは直線関係となり, グラフの上で $a$ と $b$ が求まる。一般浭使用する薬剤粉体や空隙率の ある程度大きい粉体にはよくこの直線関係が見いださ

Table I. Application of Kawakita's compression equation to tapping and vibrating compaction.

\begin{tabular}{c|c|c|c}
\hline & Piston compression & Tapping compaction & Vibrating compaction \\
\hline \multirow{2}{*}{ Equation } & $P / C=1 /(a b)+P / a$ & $N / C=1 /(a b)+N / a$ & $t / C=1 /(a b)+t / a$ \\
$a$ & $\left(V_{0}-V_{\infty}\right) / V_{0}$ & $\left(V_{0}-V_{\infty}\right) / V_{0}$ & $\left(V_{0}-V_{\infty}\right) / V_{0}$ \\
\multirow{2}{*}{$V_{\infty}$} & Volume & Volume & Volume \\
& $P \rightarrow \infty$ & $N \rightarrow \infty$ & $t \rightarrow \infty$ \\
$b$ & $\left(V_{0}-V\right) / P\left(V-V_{\infty}\right)$ & $\left(V_{0}-V\right) / N\left(V-V_{\infty}\right)$ & $\left(V_{0}-V\right) / t\left(V-V_{\infty}\right)$ \\
\hline
\end{tabular}

$P=$ applied pressure, $N=$ tapping number, $t=$ vibrating time, $C=$ degree of volume reduction, $V_{0}=1$ initial apparent volume, $\quad V=$ volume of powder under applied pressure, tapping and vibration.

* 原稿受理 昭和44年 1 月 28 日

** 正会員 法政大学工学部 小金井市緑町 2 丁目
れる. (1) (1) 式に打いて実験上特に注意を払わなければな らない点は初期容積の測定である。測定値ばらつきの 最も大きい原因となりらる。

なお， 上記の川北式はタッピング圧密，226) 振動圧密（垂直）飞も適用できる。すなわち，これら の場合はまずタッピングについては(1)拉よび(2)式の $P$

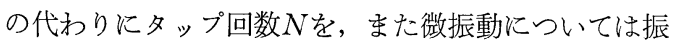
動時間 $t$ を置き換えることによって適用できる(Table I).

\section{2 川北式の特性定数}

川北式をグラフで表現すると，Fig. 1のようになる. Fig.1 亿拈いて $n$ は空吵率を表わす。 $P / C \sim P$ プロッ トについて一言すると, 厳密に考察すれば初期の部分, すなわち圧力のごく小さい場合には, 多少直線が負に 偏異することが考学られる. H. Sheinberg は球状ス テンレス粉体と銅酸化物粉体のピストン圧縮について 実験し，きれいな川北プロットを得ているが，ステン レス球粉については Fig. 2 のよらに初期部分は直線 からややはずれることを報告している.

定数 $a$ は(1)式において，Pが無限に大になるときの $C$ の值, すなわち $C_{\infty}$ 亿等しい。

$$
C_{\infty}=\left(V_{0}-V_{\infty}\right) / V_{0}=a
$$

ここに $V_{\infty}$ は粉体の実質容積である. すなわち、はまた初期空吵率でもある。 定数 $a, b$ 之粉体粒子の形状乞の他の 物性との相関性についてはすで報告 したが，aについてはある程度の相関 性は認められるが，一般に明確な関係 は得られていない。

(1)抽よび(3)式より次の式が導か礼る. $(P+1 / b)\left(V-V_{\infty}\right)=\left(V_{0}-V_{\infty}\right) / b$

$1 / b=P\left(V-V_{\infty}\right) /\left(V_{0}-V\right)$ 

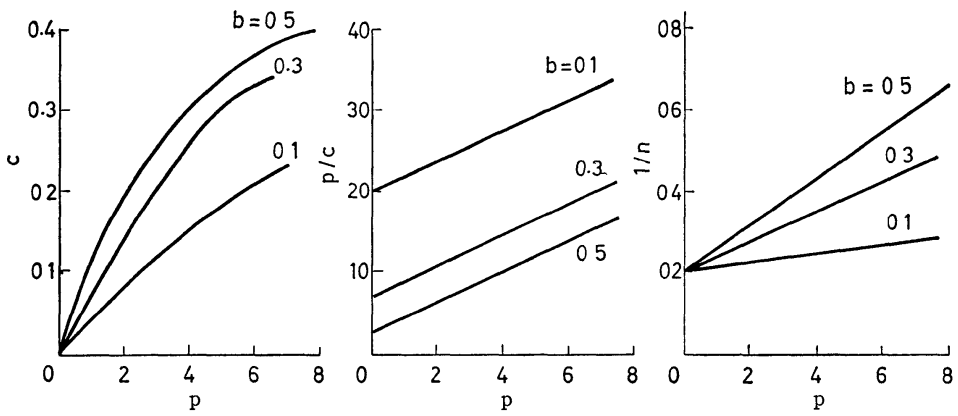

く似ているのは特もしろい。 荒川はタップ充てんの川北式 に着目し，ホワイトアランダム 微粉体について, Fig. 3 のよう なきわめてょい直線関係を示す 結果を得た。常法によってその 傾きと切片から定数 $a, b$ を求 めると Fig. 4 のようになる. ホワイトアランダムについては 粒度と, $a, b$ の関係は, $a$ 亿関 しては粒子径の減少とともに大

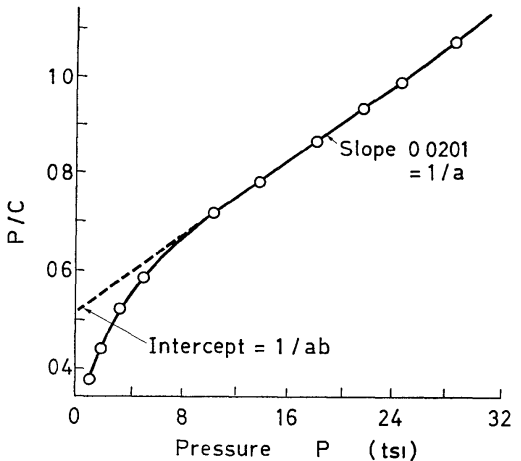

Fig. 2. Kawakita plot of $P / C$ vs. $P$ for $-100+140$ mesh, type 316 stainless steel powder (H. Sheinberg).

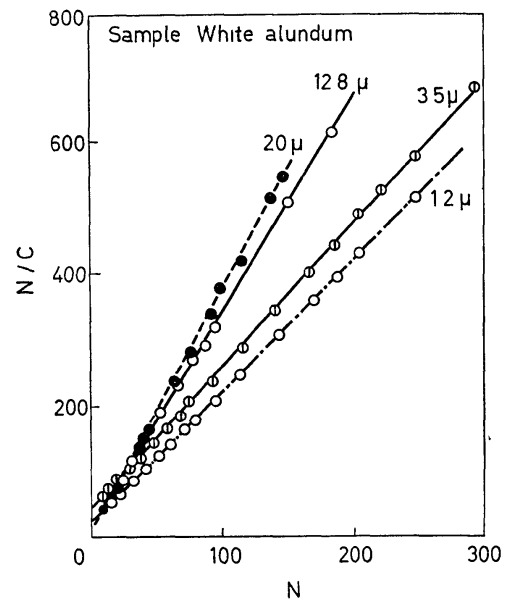

Fig. 3. An example for relation of $N$ vs. $N / C$ (M. Arakawa).

実験条件を一定にすれば(4)式において $b, V_{0}$ およ び $V_{\infty}$ は一定であるから

$$
(P+1 / b)\left(V-V_{\infty}\right)=\text { 一定 }
$$

が得られる。これはガスの van der Waals 状態式に相 似である，ガスの場合圧力に対する補正はガス分子ど らしの相互作用のプラスであり，容積汶対する補正は ガス分子の実質容積のマイナスである。式の意味もよ
きくなることを観察している。しか， $b$ については $3 \mu$ 付近に执いて 極小值を示したことはきわめて興味 がある。

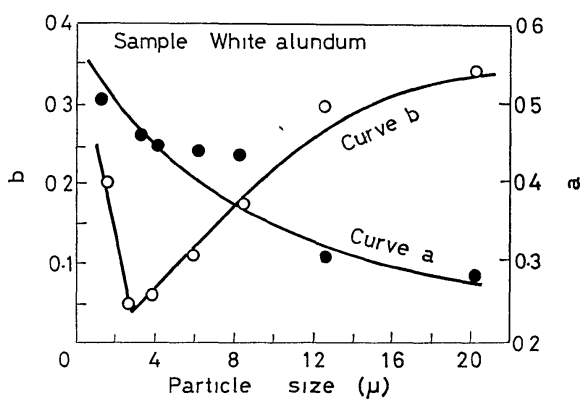

F1g. 4. Relation of $a$ and $b$ vs. particle size (M. Arakawa)

荒川は，またタッピングの川北式と久野式 $\rho_{f}-\rho_{n}=$ $\left(\rho_{f}-\rho_{0}\right) e^{-k^{n}}\left(\rho_{0}, \rho_{f}, \rho_{n}\right.$ はとれぞれ充てん前後および $n$ 回タップしたときの見掛忖密度， $k$ は充てんされや すさを示す定数）を比較検討し，定数 $k$ (この場合夕 ップ初期の $k$ の值をとる) と川北式の定数 $b$ との間に は Fig. 5 のように完全な相関性のあることを報告して いる.

要するにタップ充てんの場合, 川北式の $b$ の逆数, $1 / b$ は粉体粒子の凝集力（付着力）に関係のあること は明らかである。

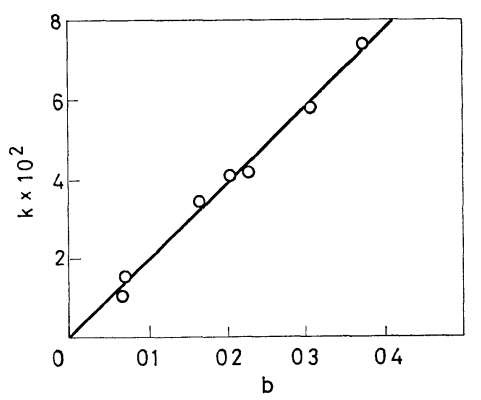

Fig. 5. Relation of $k$ vs. $b$ for white alundum (M. Arakawa). 


\section{3 粒子の理論的配列構造と実際の食い違い}

いま充てんについて一種のモデル実験をしてみる。 すなわち, 同大の球状ガラス粒子を容器に入れて空吵 率を測定してみる.そうするとだいたい空吵率は38〜 40\%である。一方理論的には同大球の配列は Table II に示され, ちようど接触点の数が 8 の場合に相当する. また非常にまるい球状ガラス粉体をピストン王縮して， 粒子がこわれる直前の最も密に充てんしたと考えられ る状態の空隙率を測定すると, Table III のよらにだ いたい37\%付近である.すなわち，実際上のガラス球 粉の最密充てんは37\%付近であって，けっして理論上 の $25.95 \%$ にはならない.すなわち，このようなモデ ル的実験でも理論と実際はなかなか合致しない.

Table II. Packing characteristics.

\begin{tabular}{l|c|c}
\hline \multicolumn{1}{c|}{ Type of packing } & Number of contacts & Porosity (\%) \\
\hline Cubic & 6 & 47.64 \\
Orthorhombic & 8 & 39.54 \\
Rhombohedral & 12 & 2595 \\
Tetragonalsphenoidal & 10 & 3019 \\
\hline
\end{tabular}

Table III. Porosity of spherical glass powder just before the breaking of the particles.

\begin{tabular}{c|c}
\hline Average particle diameter (mm) & Porosity (\%) \\
\hline 1205 & 36.8 \\
0.920 & 37.3 \\
0.775 & 373 \\
0.650 & 37.8 \\
0.545 & 36.0 \\
0.460 & 352 \\
0385 & 37.1 \\
0324 & 357 \\
\hline
\end{tabular}

\section{4 各種圧縮式の吟味}

粉体の王縮式については, 圧力と容積変化の関係を 表現する式についても多数あるが，表現がまちまちで あるので一応比較しやすいように統一した記号で表現 しな掞すと Table IV のようになる.

Table IV に示した式のらち, Murray, Konopicky の式は Athyの式と本質的に同じであり, 谷本, 津和 の式は川北の式と同じであり，西原の式は Nutting の 式と同じである。したがって，これらの式を除いた残 りの式について, 空隙率 $n$ について, 式自身に合理 性があるかどらかをみると Table V のよらになる。 Table V より明らかなように式として 合理的で, 矛 盾のないのは Athy と川北の式である. 一般に実験式 と称するものの中には式として自己矛盾のあるものも あるから，合理的でないといって価值がないといらこ
Table IV. Various equations represented by the same notations.

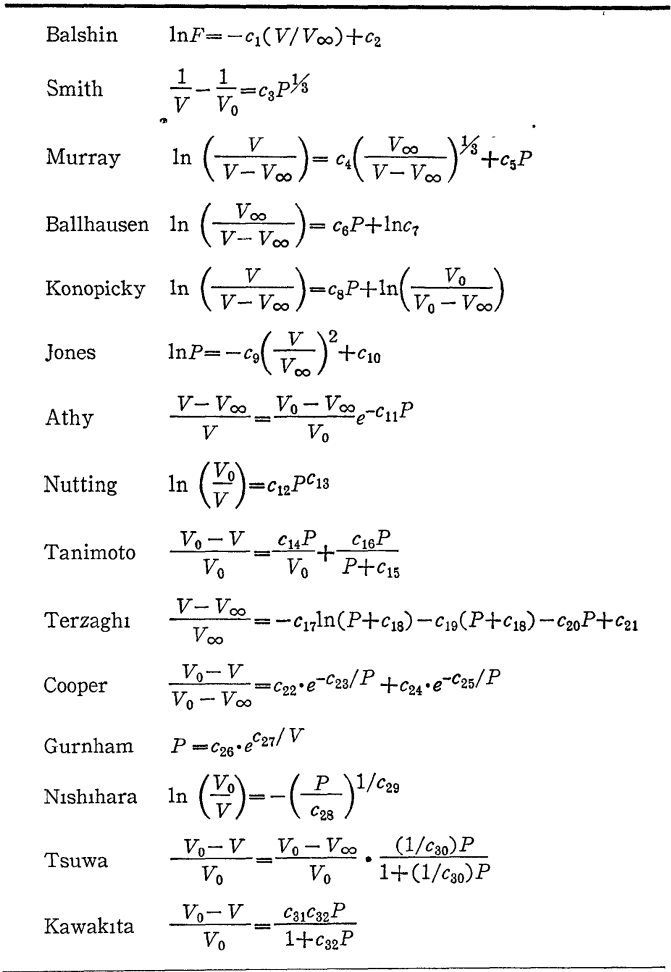

$V_{0}=1$ intial apparent volume of powder, $\quad V=$ volume of powder under the applied pressure $P, V_{\infty}=$ net volume of powder, $c_{1} \cdots \cdots c_{32}=$ constants

In the equation of Burr,the density of a powder is expressed as the function of pressures and we omit this equation from the list because of 1 ts unconcrete expression. In Athy's equation we substituted the depth of a burial with a pressure term $P$. In ordinary case it is used as Athy's compression equation and we justıfied in takıng this manner. As for Nuttıng's equation which includes a time dependent factor, it is very important from the standpoint of rheology, but it is treated that the measuring time is taken as a constant in order to compare with other equations.

とはいえない。

\section{5 圧 縮 理 論}

圧力と容積変化の関係を導く理論はいくつか発表さ れている. 王縮過程をモデル化して考察したものや， 確率論的な立場をとるものやいろいろある．若林はモ ールの応力円と粒子の配列状態の変化のしかたを関係 づけることによって応力と圧縮の関係を論じている. かれによれば最終的に得られた圧縮理論式はTerzaghi の式と本質的に同様であることを指摘している.

著者はやはりモールの応力円を使って次のように压 縮理論式を導いた。詳細な説明は省略するが， Fig. 6 に扣いて，限界応力状態にある粉体の応力状態が 円 $K_{1}$ で示されているとする. 図で $\sigma_{1}, \sigma_{2}$ はそれぞれ最 大, 最小主応力を表わし, $\varphi$ は内部摩擦角, $\tau$ はせん 断応力を表わす.ささこのとき最大主応力 $\sigma_{1}$ が $\Delta \sigma_{1}$ 
Table V. Comparison of porosities derived from various equations.

\begin{tabular}{|c|c|c|c|c|}
\hline Author & Porosity $(n=)$ & $P \rightarrow 0$ & $P \rightarrow \infty$ & $\begin{array}{l}\text { Necessary } \\
\text { condition }\end{array}$ \\
\hline Balshin & $1-\frac{c_{1}}{c_{2}-\ln P}$ & 1 & 1 & $c_{1} \neq 0$ \\
\hline Smith & $n_{0}-c_{3} V_{\infty} P^{1 / 3}$ & $n_{0}$ & $\begin{array}{l}-\infty\left(c_{3}>0\right) \\
+\infty \quad\left(c_{3}<0\right)\end{array}$ & $c_{3} \neq 0$ \\
\hline Ballhausen & $\frac{1}{1+c_{7} \cdot \exp \left(c_{6} P\right)}$ & $\frac{1}{1+c_{7}}$ & 0 & $\begin{array}{l}c_{6} \neq 0 \\
c_{7} \neq 0\end{array}$ \\
\hline Jones & $1-\left(\frac{c_{9}}{c_{10}-\ln P}\right)^{1 / 2}$ & 1 & 1 & $c_{9} \neq 0$ \\
\hline Athy & $n_{0} \cdot e^{-c_{11} P}$ & $n_{0}$ & 0 & $c_{11} \neq 0$ \\
\hline Nuttıng & $1-\left(\frac{V_{\infty}}{V_{0}}\right) e^{c_{12} P^{c_{13}}}$ & $n_{0}$ & $\begin{array}{lll}n_{0} & & \left(c_{13}<0\right) \\
-\infty & \left(c_{12}>0,\right. & \left.c_{13}>0\right) \\
1 & \left(c_{12}<0,\right. & \left.c_{13}>0\right) \\
\end{array}$ & $\begin{array}{l}c_{12} \neq 0 \\
c_{13} \neq 0\end{array}$ \\
\hline Terzagh 1 & $1-\frac{1}{1-c_{17} \ln \left(P+c_{18}\right)-c_{19}\left(P+c_{18}\right)+c_{21}}$ & $1-\frac{1}{1-c_{17} \ln c_{18}-c_{19} c_{18}+c_{21}}$ & 1 & \\
\hline Cooper & $1-\frac{\left(V_{\infty} / V_{0}\right)}{1-n_{0} c_{22} \cdot \exp \left(-c_{23} / P\right)}$ & $n_{0}$ & $\frac{1-c_{22}}{\left(1 / n_{0}\right)-c_{22}}$ & $\begin{array}{l}c_{22} \neq 0 \\
c_{23} \neq 0\end{array}$ \\
\hline Kawakita & $\frac{n_{0}}{1+\left(V_{\infty} / V_{0}\right) c_{26} P}$ & $n_{0}$ & 0 & $c_{26} \neq 0$ \\
\hline
\end{tabular}

$n=$ porosity, $\quad n_{0}=$ initial porosity

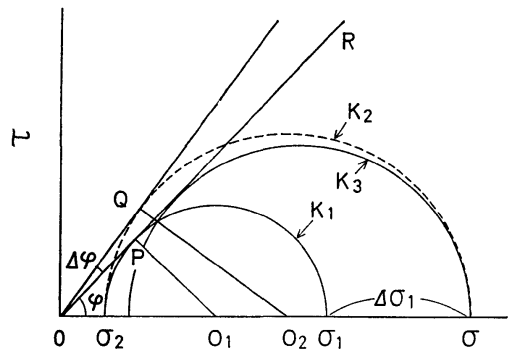

Fig. 6. Mohr's stress circle.

だけ增しても粉体の場合は, 粒子の再配列が行なわれ てただちに $\sigma_{2}$ が変わるわけではない，その応力状態 は一応 $K_{2}$ で示されるよらな状態になる。 $K_{2}$ は不安 定であるから, 結局 $\sigma_{2}$ も変化して安定な $K_{3}$ の状態 になっていく．ここでモール円 $K_{2}$ が限界線 $O R$ を こえる量を図のように $\Delta \varphi$ で表わすことにすれば, 粉 体内の粒子の配列状態が変化する確率は $\Delta \varphi$ によって 表わすことができると考党てよいであろう，粒子の配 列が変わる確率性充てんのとき大きく, 密充てんに おいてはわずかである。 $\Delta \varphi$ の值について子図からわ かるように定性的には同様であり, ある一定の $\Delta \sigma_{1}$ の 増加分に対して $\sigma_{1}$ の值が小さいときに $\Delta \varphi$ の值は大 きく, $\sigma_{1}$ の值が大きな密充てんの状態では $\Delta \varphi$ の值 が小さくなる.

さて図から $\Delta \varphi$ の值を求める. Rankine の係数を $K$ とすると，

$$
K=\frac{1-\sin \varphi}{1+\sin \varphi}, \quad \sigma_{2}=K \sigma_{1}
$$

であるから，

$$
\begin{aligned}
d \sigma_{1} & =2\left(\overline{O_{2} Q}-\overline{O_{1} P}\right)=\left\{(1+K) \sigma_{1}+d \sigma_{1}\right\} \sin (\varphi+\Delta \varphi) \\
& -(1+K) \sigma_{1} \sin \varphi \fallingdotseq d \sigma_{1} \sin \varphi+(1+K) \sigma_{1} \Delta \varphi \cos \varphi
\end{aligned}
$$

ゆえに

$$
\Delta \varphi=\frac{1}{1+K} \cdot \frac{1-\sin \varphi}{\cos \varphi} \cdot \frac{d \sigma_{1}}{\sigma_{1}}
$$

また

$$
\sin \varphi=\frac{1-K}{1+K}, \quad \cos \varphi=\frac{2 \sqrt{K}}{1+K}
$$

であるから

$$
\Delta \varphi=\frac{\sqrt{K}}{1+K} \cdot \frac{d \sigma_{1}}{\sigma_{1}}
$$

さて(11)式に括いて， $\Delta \varphi$ は粒子の配列変化を生ずる 確率を表わすものであるから，充てん状態を表わす何 かの量に比例すると考㝋てよいであろら。

(a) $\Delta \varphi$ が空隙率 $n$ の減少に比例するとき,

$$
-d n=k \frac{d P}{P}
$$

ただし比例定数を $k$ で表わす (以下同様).

これは Gurnham の式に一致し, Smith の式に近い 理論式を得たことになる.

(b) $\Delta \varphi$ が体積ひずみ $\varepsilon$ の変化に比例するとき,

$$
-d \varepsilon=-\frac{d n}{(1-n)}=k \frac{d P}{P}
$$

これは Nutting の式に近い理論式になる.

(c) $\Delta \varphi$ がかさべり度 $C$ (粉体容積減少度) の変化に 比例するとき，

$$
-d C=-\frac{V_{\infty}}{V_{0}} \frac{d n}{(1-n)^{2}}=k \frac{d P}{P}
$$

これは Balshin の式に一致し, Terzaghi の式に近 w.

(d) $\Delta \varphi$ が $-\frac{d n}{n P}$ に比例するとき，

$$
-\frac{d n}{n P}=k \frac{d P}{P}
$$

これは Athy の式に一致する. 
(e) $\Delta \varphi$ が $-\frac{d n}{n^{2} P}$ に比例するとき，

$$
-\frac{d n}{d P}=k n^{2}
$$

これは川北の式に一致する.

以上は試及に $\Delta \varphi$ がいろいろな量に比例するとした 場合にいろいろな圧縮式が導かれることを示したが， 本当に $\Delta \varphi$ が 何に比例すると考兄なければならないか については今後の論議が必要である.

梅屋はひずみ $\varepsilon$ と応力 $\sigma$ との間には圧縮係数を $X$ と して, 一般に $\varepsilon=X \sigma$ の関係が市ることから, 粉体材 料についての压縮保数に対する考察を行なった結果,

$$
\sigma=K \cdot \varepsilon^{(1+a)}
$$

の理論式を得た。ただし $K, a$ は定数, この式は

$$
\varepsilon=K^{-\frac{1}{1+\alpha}} \cdot \frac{1}{\sigma^{1+a}}
$$

と書き直すことができるから，Nutting の実験式と同 じである。

若林, 梅屋の上うな粉体材料の特性を考学て理論を 構成する立場に対して, 以下に述べる最上, 早川, 大 矢根の理論のように, 粉体をミク口的な不連続体と考 えて個々の粒子の充て几条件あるいは個々の粒子の圧 縮抵抗から集合体としての粉体の力学的挙動を考察し ていく立場がある。

最上は，一定容積の中に粒子を分配する確率と熱力 学的考察とから次の理論式を得た。

$$
P=K_{0}\left(V_{0}-V\right)+N K\left(\frac{1}{V}-\frac{1}{V_{0}}\right)
$$

ただし $P$ : 圧力, $V_{0}$ : 初期容積, $V$ : 容積, $N$ : 粒子の総数, $K_{0}$ と $K$ は定数である. (19)式の右辺の第 1 項は弾性エネルギ変化の項であり, 高圧でなければ 第 1 項を無視して,

$$
\frac{V_{0}-V}{V_{0}}=\frac{\left(V_{0} / N K\right) P}{1+\left(V_{0} / N K\right) P}
$$

と書き替えることができるから，川北の式と本質的に 同じである。

なお，最上は上記の理論を改訂して，

$$
S=\frac{1}{A} \log \frac{P-B}{P_{0}-B}
$$

の式を提出している. ここで $S:$ ピストンの変位, $A$ : ピストンの断面積, $P_{0}$ : 初期加圧, $P$ : 圧力, $B:$ 定数である.この式は

$$
-\frac{d n}{d P}=\frac{V_{\infty}(1-n)^{2}}{(P-B)}
$$

と書き替えることができるから，Terzaghi の式と本 質的に等しい理論式を導き出したことになる.

早川は 1 個の球に対応する充てん空間を表わす単位 細胞についてのエネルギ的な考察に粒子間のポテンシ ヤルを導入し, 粒子間ポテンシャルの関数としていろ いろな型を考えることから, Athy 式, Balshin 式,
川北式などを理論的に誘導している.

大矢根は粉体内の個々の粒子の変形抵抗と, それら 粒子の集合体としての粉体の力学的挙動とを関係づけ ることから次の理論式を得ている.

$$
\left.q=\frac{n\left(1-\varepsilon_{t}\right)}{\pi(1-\varepsilon)}\left\{200\left(\frac{\mu \pi}{16}+\frac{1}{3}\right) \varepsilon^{2}+140 \frac{\mu \pi}{8}+\frac{1}{2}\right) \varepsilon\right\}
$$

ここで $q$ : 垂直方向の圧縮応力, $\varepsilon$ : 圧縮率, $\varepsilon_{t}$ : 真 の密度になるまでの圧縮率， $n$ : 粒子の $1 / 8$ 球面に隣 接する他の粒子の数, $\mu$ : 粉体内の内部摩擦係数であ る. (23)式は $\varepsilon^{2}$ の項 $(\varepsilon<1)$ を無視すれば,

$$
\frac{V_{0}-V}{V_{0}}=\frac{(1 / \alpha) P}{1+(1 / \alpha) P}
$$

と書き替えられるから, 本質的には川北の式と同じで ある.ただし $\alpha$ は定数，(23)式における圧縮率 $\varepsilon$ はかさ ベり度に相当する。

このほかにも粉体内の圧力分布, 密度分布を表わす 理論として, 津和, 明田の理論や西原, 郡, 谷の理論 があるが，ここでは圧力-容積の関係の理論のみを論 述した。

今後この方面の理論の発展を期待し, あわせて粉体 粒子の基礎的物性とのつながりについての解明の進展 に期待したい.

（昭和43年10月 4 日 第 6 回粉体に関する討論会にて講演）

\section{参 考 文 献}

1) Kawakita, K., and Y. Tsutsumi, Bull. Chem. Soc. Japan, 39, 1364 (1966).

2）川北公夫, 津々見雄文, 法政大学工学部研究集報, No. 5, 5 (1968).

3）川北公夫, 津々見雄文, 化学工学, 32, 750 (1968).

4）川北公夫, 津々見雄文, 法政大学工学部研究集報, No. 5，1，(1968).

5）川北公夫，津々見雄文，化学と工業， 20, No. 5，443 (1967).

6) Lüdde, K.-H., and K. Kawakita, Die Pharmazie, Heft 7, s. 393 (1966).

7) Kawakita, K., and Y. Tsutsumi, J. App. Phys. Japan, 4, No. 1, 56 (1965).

8）川北公夫，材料， 13，421 (1964).

9）川北公夫，津々見雄文，材料， 14，707 (1965).

10）川北公夫, 科学, 26, No. 3, 149 (1956).

11）川北公夫, 高峰研究年報, 8, 83 (1956).

12) 同上, 8, 87 (1956).

13）同上, 8, 92 (1956).

14）同上, 10, 93 (1958).

15）川北公夫，粉体および粉末治金， 10，71（1963）.

16）同上, 10, 236 (1963).

17) Collins, R E., Transactions American Geophysical Union, 45, No. 1, 161 (1964).

18）川北公夫，津々見雄文ほか，応用物理，34，360（1965）. 
19）川北公夫，津々見雄文，応用物理，35，260（1966）.

20）川北公夫, 津々見雄文, 法政大学工学部研究集報, No. 3, 36 (1966).

21）川北公夫, 粉体と工業, 1, No. 1，44 (1969).

22）川北公夫，材料， 13，427 (1964).

23）川北公夫，粉体および粉末治金， 10，242（1963）.

24）同上, 10, 73 (1963).

25) Lüdde, K.-H., and K. Kawakita, Die Pharmazie, Heft 7, s. 399 (1966).

26）川北公夫, 津々見雄文, 法政大学工学部研究集報, No. 3, 43 (1966).

27）川北公夫，津々見雄文，応用物理， 35, No. 4, 263 (1966).

28）川北公夫, 津々見雄文, 法政大学工学部研究集報, No. 3, 49 (1966).

29) Sheinberg, H., Los Alamos Scientific Laboratory of the Univ. of California, UC-25, Metals, Ceramics, and Materials TID-4500, U.S A. (1967).

30）荒川正文，岡田隆夫，水渡英二，材料， 14， 764 (1965) ; 151 (1966).

31) Kuno, H., Proc. Fac. Eng. Keio Univ, 11, No.41, 1 (1958).
32）川北公夫, 種谷真一, 概論粉体工学, p. 57 (1967).

33）川北公夫; 津々見雄文ほか, 法政大学工学部研究集報, No. 2, 47 (1965).

34) 川北公夫, 津々見雄文, 法政大学工学部研究集報, No. 5, 1 (1968).

35）川北公夫，粉体および粉末冶金， 10，71（1963）.

36）川北公夫, 種谷真一, 概論粉体工学, p. 71 (1967).

37）若林隆夫，粉体および粉末冶金，10，83 (1963).

38）川北公夫, 津久見雄文, 粉体工学, No. 7, 51 (435) (1967).

39）渡辺 明, 梅屋 薰, 材料, 13，237 (1964).

40）最上武雄, 東大理工研究報告, 3, 168 (1949).

41) Mogami, T., J. Fac. Eng. Univ. of Tokyo, 28, 65 (1965); Trans. Japan Soc. Civil Engineers, 128, 53 (1966); 129, 39 (1966).

42）早川宗八郎, 東大理工研報告, 4, 87 (1950); 表面, 3, 409 (1965).

43）大矢根守哉，粉体および粉末冶金， 13，113 (1966).

44）津和秀夫, 明田勇蔵, 精密機械, 29, 945 (1963).

45）西原利夫, 郡 利矩, 谷 哲郎, 日本機械学会論文集, 20, 208 (1954). 